\section{A) Check for updates}

Cite this: Polym. Chem., 2020, 11 3066

Received 21st February 2020, Accepted 3rd April 2020

DOI: $10.1039 / \mathrm{d} 0$ py00286k rsc.li/polymers

\title{
Synthesis of conjugated polymers via cyclopentannulation reaction: promising materials for iodine adsorption $\uparrow$
}

\author{
Noorullah Baig, ${ }^{a, b}$ Suchetha Shetty, ${ }^{\text {a,b }}$ Saleh Al-Mousawi ${ }^{c}$ and \\ Bassam Alameddine (iD *a,b
}

\begin{abstract}
A new class of conjugated polymers is prepared by means of a versatile palladium-catalyzed cyclopentannulation reaction using a series of specially designed diethynyl aryl synthons with the commercially available 9,10-dibromoanthracene DBA monomer. The target polymers, CPP1-3, display high solubility and excellent chemical stability, which allow their structural and photophysical characterization by various instrumental analysis techniques such as gel permeation chromatography (GPC), and ${ }^{1} \mathrm{H}$ - and ${ }^{13} \mathrm{C}$-nuclear magnetic resonance (NMR), Fourier transform infrared (FTIR), UV-vis absorption, and emission spectroscopy. GPC chromatograms of CPP1-3 display a high relative weight-average $\left(M_{w}\right)$ molecular weight in the range of 15.8 to $34.3 \mathrm{kDa}$ with a polydispersity index $\left(\Theta=M_{w} / M_{n}\right)$ of $\sim 2.5$. Investigation of the iodine adsorption properties of CPP1-3 reveals their high uptake, namely 200 wt\% for CPP2, whose sorption property was sustained even after its reuse several times.
\end{abstract}

\section{Introduction}

The design of new conjugated polymers has become one of the chief topics of interest for scientific endeavors because of the importance of this latter class of materials in diverse applications, namely, light-emitting diodes (LEDs), ${ }^{1-3}$ organic solar cells, $^{4-7}$ field-effect transistors (FETs), ${ }^{8-16}$ sensors, ${ }^{17}$ optical switches, ${ }^{18-22}$ batteries, ${ }^{23}$ and thermoelectrics. ${ }^{24}$ In addition to the hitherto mentioned applications, conjugated microporous polymers (CMP) have become exceptionally eminent due to many reasons, notably their extended $\pi$-conjugation skeleton, high stability, synthesis versatility, large surface area, and excellent gas sorption properties. ${ }^{25}$

The total world energy demand is increasing rapidly as a result of the rise in global population and economic growth. It is estimated that the energy consumption will reach 778 Etta Joule by $2035 .^{26}$ In the meantime, the quest for a sustainable, efficient, low-emission energy source continues to be a global interdisciplinary research challenge. ${ }^{27}$ Wind power and solar energy are often considered potential alternatives for our current fossil-fuel based energy economy, but their sporadic

\footnotetext{
${ }^{a}$ Department of Mathematics and Natural Sciences, Gulf University for Science and Technology (GUST), Kuwait. E-mail: alameddine.b@gust.edu.kw

${ }^{b}$ Functional Materials Group - CAMB, GUST, Kuwait

${ }^{c}$ Department of Chemistry, University of Kuwait, Kuwait

$\dagger$ Electronic supplementary information (ESI) available. See DOI: 10.1039/ d0py00286k
}

nature of energy production leads to reliability concerns. ${ }^{28}$ Nuclear energy is considered to be a possible option for continuous energy production. ${ }^{29}$ Nevertheless, the successful mass production of power from nuclear fission is accompanied by the emission of several radioactive gases, such as, ${ }^{14} \mathrm{CO}_{2},{ }^{85} \mathrm{Kr},{ }^{3} \mathrm{H},{ }^{123} \mathrm{I},{ }^{125} \mathrm{I}$, and ${ }^{127-140} \mathrm{I} .{ }^{30} \mathrm{In}$ addition to the hitherto mentioned radioactive iodine, hydrogen iodide (HI) and alkyl halides are also considered hazardous due to their large heat release, involvement in metabolic processes, and long half-lives (e.g., $t_{1 / 2}=15.7 \times 10^{6}$ years for $\left.{ }^{129} \mathrm{I}\right) .{ }^{31,32}$ Consequently, in view of its threat to human health and for being a mutation source of plants and animals, there is a need for effective and longer-lasting solutions to capture and store the radioactive iodine species. ${ }^{33-35}$ Amongst the most efficient and cost-effective adsorption technologies, porous adsorbents, such as organic cages, silica gel, zeolites, activated carbon, and metal organic frameworks, have been tested for iodine capture. $^{36-40}$

Various conjugated polymers have been reported with structures ranging from linear, ${ }^{14,41}$ hypercrosslinked, ${ }^{42}$ organic frameworks, ${ }^{25,43}$ to polycyclic aromatic hydrocarbons. ${ }^{44-48}$ Nevertheless, the rigidity and stiffness of these polymers make them poorly soluble, which can be circumvented by the introduction of aliphatic side chains in order to improve their solubility in common organic solvents. However, the insertion of long peripheral chains hampers microporosity since these latter block the intrinsic pores. ${ }^{49}$ An alternative strategy to improve the solubility of conjugated polymers would be the 
insertion of spiro-centers that result in the formation of contorted structures, which prevents any aggregation caused by $\pi-\pi$ stacking. ${ }^{50-52}$ Herein we describe the synthesis of three conjugated organic polymers CPP1-3 from 9,10-dibromoanthracene DBA with various contorted aryl dialkyne comonomers 3a-c via a versatile palladium-catalyzed cyclopentannulation reaction. ${ }^{53,54}$ It is worth mentioning that the target polymers were obtained in excellent yields and were found to be highly soluble in common organic solvents. Hence, CPP1-3 were characterized by GPC, NMR, FTIR, UV-vis absorption and emission spectroscopy. In addition, the target polymers were investigated for iodine uptake applications.

\section{Experimental}

\section{Materials}

All the reactions were carried out under an inert atmosphere using dry argon. All chemical reagents were used without further purification as purchased from Aldrich, Merck, and HiMedia unless otherwise specified. The triptycene nonaflate 2c was synthesized following the literature. ${ }^{55}$ The solvents, namely, hexane, DCM, THF, benzene, toluene, diisopropylamine, DMSO, and acetone, were dried and deoxygenated by bubbling with argon gas for 30 minutes. Thin-layer chromatography (TLC) was performed on aluminum sheets coated with silica gel 60 F254 and revealed using a UV lamp.

\section{Instruments}

NMR $\left({ }^{1} \mathrm{H}: 600 \mathrm{MHz},{ }^{13} \mathrm{C}: 150 \mathrm{MHz}\right)$ spectra were recorded on a Bruker BioSpin $\mathrm{GmbH} 600 \mathrm{MHz}$ spectrometer using $\mathrm{CD}_{2} \mathrm{Cl}_{2} /$ $\mathrm{CDCl}_{3}$ as a solvent with the chemical shifts $(\delta)$ given in ppm and referred to tetramethylsilane (TMS). Electron impact highresolution mass spectra (EI-HRMS) were recorded on a Themo Fisher DFS analyzer with a standard PFK (perfluorokerosene) as lock mass. The analysed data were converted to accurate mass employing X-Calibur accurate mass calculation software. UV-Vis spectra were recorded on a Shimadzu UV1800 spectrophotometer. Photoluminescence (PL) spectra were recorded on an Agilent G9800 Cary Eclipse Fluorescence spectrophotometer. An Agilent Gel Permeation Chromatography (GPC/SEC) system equipped with two columns (PL mixed-C) and calibrated against twelve monodisperse polystyrene (PS) standards, using THF as the eluent at a flow rate of $1.0 \mathrm{~mL} \mathrm{~min}{ }^{-1}$, was employed to determine the relative weight-average $\left(M_{\mathrm{w}}\right)$, number-average $\left(M_{\mathrm{n}}\right)$ molecular weights, and polydispersity index $\left(\nexists=M_{\mathrm{w}} / M_{\mathrm{n}}\right)$ of all the reported polymers. FT-IR spectra were recorded on an FT/IR-6300 type A instrument using a $\mathrm{KBr}$ matrix.

\section{Synthesis}

Synthesis of 3a (procedure A). A Schlenk tube was charged under argon with 1-(tert-butyl)-4-ethynylbenzene $1 \mathrm{a}(0.25 \mathrm{~mL}$, $1.4 \mathrm{mmol}, 4.7$ eq.), 2,7-dibromo-9,9-dimethyl-9H-fluorene $2 \mathrm{a}$ (105 mg, 0.3 mmol, 1 eq.), $\operatorname{Pd}_{2}(\mathrm{dba})_{3}(1.6 \mathrm{mg}, 1.8 \mu \mathrm{mol}$, $6 \mathrm{~mol} \%), \mathrm{PPh}_{3}(1 \mathrm{mg}, 3.6 \mu \mathrm{mol})$, and CuI $(1 \mathrm{mg}, 6.0 \mu \mathrm{mol})$ in
$2 \mathrm{~mL}$ of degassed diisopropylamine $\left(\mathrm{iPr}_{2} \mathrm{NH}\right)$ and the solution was refluxed for 2 days. The resulting solid was filtered and washed exhaustively with petroleum ether yielding a pale pink solid (140 mg, 93\%). ${ }^{1} \mathrm{H}$ NMR (600 $\left.\mathrm{MHz}, \mathrm{CD}_{2} \mathrm{Cl}_{2}, \mathrm{ppm}\right): \delta 7.76$ (d, $2 \mathrm{H}, J=7.8 \mathrm{~Hz}, \mathrm{ArH}), 7.66$ (s, 2H, ArH), 7.56 (dd, 2H, $J=7.8$, $6.6 \mathrm{~Hz}, \mathrm{ArH}) 7.52(\mathrm{~m}, 4 \mathrm{H}, J=3.6 \mathrm{~Hz}, \operatorname{ArH}) 7.45$ (m, 4H, ArH), $1.55\left(\mathrm{~s}, 6 \mathrm{H},-\mathrm{CH}_{3}\right), 1.37\left(\mathrm{~s}, 18 \mathrm{H},-\mathrm{CH}_{3}\right) .{ }^{13} \mathrm{C} \mathrm{NMR}(150 \mathrm{MHz}$, $\left.\mathrm{CD}_{2} \mathrm{Cl}_{2}, \mathrm{ppm}\right): \delta 154.66,152.35,139.20,131.80,131.30,126.50$, 126.09, 122.94, 120.84, 90.44, 89.98, 47.47, 35.29, 31.50, 27.32. EI-HRMS: $\mathrm{m} / \mathrm{z}$ calculated for $\mathbf{M}^{\cdot+} \mathrm{C}_{39} \mathrm{H}_{38} 506.2974$ found 506.2975 .

Synthesis of $\mathbf{3 b}$. $\mathbf{3 b}$ was prepared following procedure A with 1-(tert-butyl)-4-ethynylbenzene $1 \mathrm{a}(0.25 \mathrm{~mL}, 1.4 \mathrm{mmol}, 4.7$ eq.), 2,7-dibromo-9,9'-spirobifluorene $2 \mathbf{b}$ (140 mg, $0.3 \mathrm{mmol}, 1$ eq.), $\mathrm{Pd}_{2}(\mathrm{dba})_{3}(1.5 \mathrm{mg}, 1.8 \mu \mathrm{mol}, 6 \mathrm{~mol} \%), \mathrm{PPh}_{3}(1 \mathrm{mg}, 3.6 \mu \mathrm{mol})$, and $\mathrm{CuI}(1 \mathrm{mg}, 6.0 \mu \mathrm{mol})$ in $2 \mathrm{~mL}$ of degassed diisopropylamine $\left(\mathrm{iPr}_{2} \mathrm{NH}\right)$. Pale yellow solid $(282 \mathrm{mg}, 100 \%) .{ }^{1} \mathrm{H}$ NMR (600 MHz, $\mathrm{CD}_{2} \mathrm{Cl}_{2}, \mathrm{ppm}$ ): $\delta 7.95$ (d, 2H, $\left.J=7.8 \mathrm{~Hz}, \mathrm{ArH}\right), 7.90$ (d, $2 \mathrm{H}, J=7.8 \mathrm{~Hz}, \mathrm{ArH}), 7.60(\mathrm{dd}, 2 \mathrm{H}, J=7.8,6.6 \mathrm{~Hz}, \mathrm{ArH}) 7.46$ (t, 2H, $J=7.8 \mathrm{~Hz}, \operatorname{ArH}), 7.36$ (bs, 8H, ArH), $7.20(\mathrm{t}, 2 \mathrm{H}, J=7.8$ $\mathrm{Hz}, \mathrm{ArH}), 6.92$ (s, 2H, ArH), 6.80 (d, 2H, $J=7.8 \mathrm{~Hz}, \operatorname{ArH}), 1.32$ $\left(\mathrm{s}, 18 \mathrm{H},-\mathrm{CH}_{3}\right) \cdot{ }^{13} \mathrm{C} \mathrm{NMR}\left(150 \mathrm{MHz}, \mathrm{CD}_{2} \mathrm{Cl}_{2}, \mathrm{ppm}\right): \delta 151.74$, 149.26, 147.77, 141.85, 141.10, 131.36, 131.08, 128.10, 127.99, 126.93, 125.39, 123.89, 122.98, 120.42, 120.24, 119.90, 90.17, 88.76, 65.57, 34.64, 30.83. EI-HRMS: $\mathrm{m} / \mathrm{z}$ calculated for $\mathbf{M}^{{ }^{+}}$ $\mathrm{C}_{49} \mathrm{H}_{40} 628.3130$ found 628.3132 .

Synthesis of 3c. 3c was prepared following procedure A with 1-(tert-butyl)-4-ethynylbenzene $1 \mathrm{a}(1.0 \mathrm{~mL}, 5.5 \mathrm{mmol}, 4.7$ eq.), triptycene nonaflate $2 \mathrm{c}(1.0 \mathrm{~g}, 1.17 \mathrm{mmol}, 1$ eq. $), \mathrm{Pd}_{2}(\mathrm{dba})_{3}$ (6.7 mg, $7.0 \mu \mathrm{mol}, 6 \mathrm{~mol} \%$ ), $\mathrm{PPh}_{3}(27 \mathrm{mg}, 11 \mu \mathrm{mol})$ and $\mathrm{CuI}$ (4.5 mg, $23 \mu \mathrm{mol}$ ) in $7 \mathrm{~mL}$ of degassed diisopropylamine $\left(\mathrm{iPr}_{2} \mathrm{NH}\right)$. White solid (567 mg, 66\%). ${ }^{1} \mathrm{H}$ NMR $(600 \mathrm{MHz}$, $\left.\mathrm{CD}_{2} \mathrm{Cl}_{2}, \mathrm{ppm}\right): \delta 7.68$ (d, $\left.4 \mathrm{H}, J=8.4 \mathrm{~Hz}, \mathrm{ArH}\right), 7.54-7.51(\mathrm{~m}$, $8 \mathrm{H}, \operatorname{ArH}), 7.21$ (s, 2H, $\operatorname{ArH}), 7.09$ (q, $4 \mathrm{H}, J=5.4 \& 2.4 \mathrm{~Hz}, \operatorname{ArH}$ ), $6.06\left(\mathrm{~s}, 2 \mathrm{H}\right.$, triptycene-CH), $1.42\left(\mathrm{~s}, 18 \mathrm{H},-\mathrm{CH}_{3}\right) .{ }^{13} \mathrm{C} \mathrm{NMR}$ $\left(150 \mathrm{MHz}, \mathrm{CD}_{2} \mathrm{Cl}_{2}, \mathrm{ppm}\right): \delta 152.78,147.63,145.28,132.00$, 128.46, 126.17, 126.03, 124.45, 120.65, 119.14, 94.86, 86.67, 52.66, 35.37, 31.50. EI-HRMS: $m / z$ calculated for $\mathbf{M}^{\cdot+} \mathrm{C}_{44} \mathrm{H}_{38}$ 566.2974 found 566.2976

Synthesis of TBPE (procedure B). A Schlenk tube was charged under argon with 1-bromo-4-(tert-butyl)benzene 4a (0.4 mL, $2.3 \mathrm{mmol}, 1 \mathrm{eq}$.$) , ethynyltrimethylsilane (TMSA,$ $0.17 \mathrm{~mL}, 1.2 \mathrm{mmol}, 0.5$ eq.), $\mathrm{Pd}\left(\mathrm{PPh}_{3}\right)_{2} \mathrm{Cl}_{2}$ (98 mg, $0.14 \mathrm{mmol}$, $6 \mathrm{~mol} \%$ ), 1,8-diazabicyclo[5.4.0]undec-7-ene (DBU, $2.1 \mathrm{~mL}$, $14 \mathrm{mmol}$ ), and CuI (45 mg, $0.23 \mathrm{mmol}$ ) in $30 \mathrm{~mL}$ of a degassed benzene/water mixture $(2: 3 \mathrm{v} / \mathrm{v})$. The reaction mixture was refluxed overnight and the solvent was then evaporated under reduced pressure. The resulting residue was extracted with ethyl acetate from an aqueous solution of $10 \% \mathrm{HCl}(80 \mathrm{~mL})$ and the organic layer was washed with a brine solution followed by deionized water $(100 \mathrm{~mL} \times 2)$. The desired product was isolated by silica gel column chromatography, using ethyl acetate/hexane $(10: 90 \mathrm{v} / \mathrm{v})$ as the eluent. Pale yellow solid (182 mg, 54\%). ${ }^{1} \mathrm{H}$ NMR (600 MHz, $\left.\mathrm{CD}_{2} \mathrm{Cl}_{2}, \mathrm{ppm}\right): \delta 7.50$ (d, $4 \mathrm{H}, J=8.4 \mathrm{~Hz}, \mathrm{ArH}), 7.43$ (d, $4 \mathrm{H}, J=8.4 \mathrm{~Hz}, \operatorname{ArH}), 1.37$ (s, 18H, $\left.-\mathrm{CH}_{3}\right) .{ }^{13} \mathrm{C} \mathrm{NMR}\left(150 \mathrm{MHz}, \mathrm{CD}_{2} \mathrm{Cl}_{2}, \mathrm{ppm}\right): \delta$ 151.56, 131.15, 
125.41, 120.31, 88.72, 34.66, 30.89. EI-HRMS: $m / z$ calculated for $\mathrm{M}^{++} \mathrm{C}_{22} \mathrm{H}_{26} 290.2035$ found 290.2037.

Synthesis of CPM (procedure C). A Schlenk tube was charged under argon with 9,10-dibromoanthracene DBA (50 mg, $0.15 \mathrm{mmol}, 1$ eq.), 1,2-bis(4-(tert-butyl)phenyl)ethyne TBPE (95 mg, 0.33 mmol, 2.2 eq.), $\mathrm{Pd}_{2}(\mathrm{dba})_{3}$ (13 mg, $15 \mu \mathrm{mol}$, $10 \mathrm{~mol} \%)$, Tris(o-tolyl $)$ phosphine $\left(\mathrm{P}(o \text {-tol })_{3}, 4.5 \mathrm{mg}, 15 \mu \mathrm{mol}\right)$, KOAc (73 mg, $0.75 \mathrm{mmol}$ ) and $\mathrm{LiCl}(13 \mathrm{mg}, 0.3 \mathrm{mmol})$ in $5 \mathrm{~mL}$ of a degassed DMF/toluene solution mixture $(1: 1, \mathrm{v} / \mathrm{v})$. The solution was refluxed overnight and the solvent was evaporated under reduced pressure. The resulting mixture was dissolved in DCM and extracted with a saturated solution of $\mathrm{NaHCO}_{3}$ $(50 \mathrm{~mL} \times 2)$. The combined organic layer was washed with deionized water $(100 \mathrm{~mL} \times 3)$, concentrated, and the product was precipitated by adding acetone. The precipitate was isolated by filtration under reduced pressure over a Millipore ${ }^{\circledR}$ filter and washed exhaustively with acetone. Green solid (183 mg, 74\%). ${ }^{1} \mathrm{H}$ NMR (600 MHz, $\left.\mathrm{CD}_{2} \mathrm{Cl}_{2}, \mathrm{ppm}\right): \delta 7.67$ (d, $2 \mathrm{H}, J=6.6 \mathrm{~Hz}$, $\operatorname{ArH}), 7.49$ (d, 2H, $J=8.6 \mathrm{~Hz}, \operatorname{ArH}), 7.44$ (s, 8H, ArH) $7.34(\mathrm{t}$, $2 \mathrm{H}, J=7.2 \mathrm{~Hz}, \mathrm{ArH}), 7.30$ (d, 8H, $J=2.3 \mathrm{~Hz}, \mathrm{ArH}), 1.35$ (s, 18H, $\left.-\mathrm{CH}_{3}\right), 1.25$ (s, $\left.18 \mathrm{H},-\mathrm{CH}_{3}\right) .{ }^{13} \mathrm{C}$ NMR (150 MHz, $\left.\mathrm{CD}_{2} \mathrm{Cl}_{2}, \mathrm{ppm}\right)$ : $\delta 151.28,150.44,141.49,139.85,138.88,138.77,134.78$, 132.68, 130.86, 130.39, 128.95, 128.35, 126.37, 125.74, 125.67, 125.47, 35.20, 35.03, 31.79, 31.62. EI-HRMS: $m / z$ calculated for $\mathrm{M}^{\cdot+} \mathrm{C}_{58} \mathrm{H}_{58} 754.4538$ found 754.4539 .

Synthesis of polymer CPP1 (procedure D). 9,10Dibromoanthracene DBA (40 mg, $0.12 \mathrm{mmol}, 1 \mathrm{eq}$.), 3a (60 mg, $0.12 \mathrm{mmol}, 1$ eq. $), \mathrm{Pd}_{2}(\mathrm{dba})_{3}(10 \mathrm{mg}, 12 \mu \mathrm{mol}, 10 \mathrm{~mol} \%$.), $\mathrm{P}(o-$ tol $)_{3}(5 \mathrm{mg}, 18 \mu \mathrm{mol})$, KOAc (58 mg, $\left.0.6 \mathrm{mmol}\right)$, and $\mathrm{LiCl}$ (10 $\mathrm{mg}, 0.25 \mathrm{mmol}$ ) were refluxed in $2.4 \mathrm{~mL}$ of a $1: 1 \mathrm{DMF} /$ toluene mixture in a Schlenk tube under argon. After 4 days of reaction, the solvent was evaporated under reduced pressure and the resulting residue was dissolved in $\mathrm{CHCl}_{3}$ and extracted with a saturated solution of $\mathrm{NaHCO}_{3}(50 \mathrm{~mL} \times 2)$. The organic layer was washed with deionized water $(100 \mathrm{~mL} \times 3)$, concentrated, and precipitated by adding acetone. The green solid was filtered and washed with water, methanol, and acetone and then dried under vacuum. Green solid (53 mg, 86\%). ${ }^{1} \mathrm{H}$ NMR (600 MHz, $\left.\mathrm{CDCl}_{3}, \mathrm{ppm}\right): \delta 8.10-7.88$ (m, 4H, ArH), 7.77 (bd, 2H, ArH), 7.53-7.34 (bm, 11H, ArH) and 1.43-1.36 (br, $\left.15 \mathrm{H},-\mathrm{CH}_{3}\right) .{ }^{13} \mathrm{C} \mathrm{NMR}\left(150 \mathrm{MHz}, \mathrm{CDCl}_{3}, \mathrm{ppm}\right): \delta$ 153.77, $149.75,140.86,139.74,138.19,137.82$, 136.12, 134.26, 132.14, 130.53 , 130.50, 130.04, 129.33, 128.26, 126.40, 125.82, 125.11, 119.75, 46.45, 34.60, 31.37, 26.73; GPC traces: $M_{\mathrm{w}}=15800 \mathrm{Da}$, $M_{\mathrm{n}}=6600 \mathrm{Da}, \nexists=2.4$; FTIR $\left(\mathrm{KBr}, \mathrm{cm}^{-1}\right): 2960,1626,1436$; UVvis: (THF, $\left.10^{-6} \mathrm{M}\right), \lambda_{\max }[\mathrm{nm}]=340$ and 450 .

Synthesis of polymer CPP2. CPP2 was prepared following procedure D with 9,10-dibromoanthracene DBA (53 mg, $0.16 \mathrm{mmol}, 1$ eq.), $3 \mathbf{b}$ (100 mg, $0.16 \mathrm{mmol}, 1$ eq.), $\mathrm{Pd}_{2}(\mathrm{dba})_{3}$ (15 mg, $16 \mu \mathrm{mol}, 10 \mathrm{~mol} \%$.), $\mathrm{P}(o \text {-tol })_{3}(7 \mathrm{mg}, 24 \mu \mathrm{mol})$, KOAc (78 $\mathrm{mg}, 0.8 \mathrm{mmol})$ and $\mathrm{LiCl}(13 \mathrm{mg}, 0.32 \mathrm{mmol})$ which were refluxed in $3.2 \mathrm{~mL}$ of a $1: 1 \mathrm{DMF} /$ toluene degassed solution mixture in a Schlenk tube under argon for 4 days. Green solid (100 mg, 97\%). ${ }^{1} \mathrm{H}$ NMR (600 MHz, $\left.\mathrm{CDCl}_{3}, \mathrm{ppm}\right): \delta 7.86-7.64$ (m, 4H, ArH), 7.33-6.96 (bm, 21H, ArH), 1.43-1.38 (br, 9H, $\left.\mathrm{CH}_{3}\right) .{ }^{13} \mathrm{C} \mathrm{NMR}\left(150 \mathrm{MHz}, \mathrm{CDCl}_{3}, \mathrm{ppm}\right): \delta$ 150.22, 149.53,
$148.96,141.77,140.54,138.81,138.12,137.56,136.71,133.65$, $131.87,130.51,130.22,129.83,127.82,127.67,127.02,125.75$, 125.02, 123.89, 119.95, 66.08, 34.58, 31.40; GPC traces: $M_{\mathrm{w}}=$ $34300 \mathrm{Da}, M_{\mathrm{n}}=12800 \mathrm{Da}, \nexists=2.6$; FTIR $\left(\mathrm{KBr}, \mathrm{cm}^{-1}\right): 2964$, 1682, 1428, 730; UV-vis: (THF, $\left.10^{-6} \mathrm{M}\right), \lambda_{\max }[\mathrm{nm}]=340$ and 450.

Synthesis of polymer CPP3. CPP3 was prepared following procedure D with 9,10-dibromoanthracene DBA (67 mg, $0.2 \mathrm{mmol}, 1$ eq.), 3c (113 mg, $0.2 \mathrm{mmol}, 1$ eq.), $\operatorname{Pd}_{2}(\mathrm{dba})_{3}$ (18 mg, $20 \mu \mathrm{mol}, 10 \mathrm{~mol} \%$.), P(o-tol) $)_{3}(9 \mathrm{mg}, 30 \mu \mathrm{mol})$, KOAc (105 $\mathrm{mg}, 1.0 \mathrm{mmol})$ and $\mathrm{LiCl}(16 \mathrm{mg}, 0.4 \mathrm{mmol})$ which were refluxed in $4 \mathrm{~mL}$ of a degassed 1:1 DMF/toluene solution mixture in a Schlenk tube under argon for 4 days. Green solid (105 mg, 91\%). ${ }^{1} \mathrm{H}$ NMR (600 $\left.\mathrm{MHz}, \mathrm{CDCl}_{3}, \mathrm{ppm}\right): \delta 8.04$ (br, $4 \mathrm{H}, \mathrm{ArH}), 7.58-6.86$ (bm, 17H, ArH), 5.75 (br, 2H, triptycene$\mathrm{CH}), 1.44$ (br, 9H, $\left.-\mathrm{CH}_{3}\right) .{ }^{13} \mathrm{C} \mathrm{NMR}\left(150 \mathrm{MHz}, \mathrm{CDCl}_{3}, \mathrm{ppm}\right): \delta$ 154.72, 149.84, 141.53, 140.43, 138.64, 137.19, 132.57, 132.09, 129.79, 129.71, 129.04, 128.23, 125.30, 125.12, 124.81, 120.87, 51.94, 31.52, 30.93; GPC traces: $M_{\mathrm{w}}=32200 \mathrm{Da}, M_{\mathrm{n}}=11600$ Da, $D=2.7$; FTIR $\left(\mathrm{KBr}, \mathrm{cm}^{-1}\right)$ : 2960, 1432; UV-vis: (THF, $10^{-6}$ M), $\lambda_{\max }[\mathrm{nm}]=395,445$ and 470 .

\section{Results and discussion}

\section{Synthesis of comonomers}

Scheme 1 shows the synthesis of the dialkyne comonomers 3a-c i.e. 9,9-dimethylfluorene $3 \mathbf{a}$, spiro bifluorene $\mathbf{3 b}$, and triptycene 3c. The aforementioned building blocks were prepared by reacting 1-(tert-butyl)-4-ethynylbenzene 1a with either the dibromo derivatives $\mathbf{2 a}$ and $\mathbf{2 b}$ or nonaflate synthon $\mathbf{2 c}$ via a conventional palladium-catalyzed Sonogashira cross-coupling reaction. ${ }^{56}$ Comonomers $\mathbf{3 a - c}$ were isolated in very good yields ( $\sim 66-100 \%)$ and have excellent solubility in common organic solvents, namely, dichloromethane, chloroform, tetrahydrofuran, and toluene. It is noteworthy that the formation of 3a-c was confirmed by ${ }^{1} \mathrm{H}$ - and ${ }^{13} \mathrm{C}-\mathrm{NMR}$ spectroscopy, as well as EI-HRMS (see Fig. 3 and Fig. S1-3, S9-11, and S18-20 in the ESI†).

Fig. 1 shows the representative ${ }^{1} \mathrm{H}$ - and ${ }^{13} \mathrm{C}-\mathrm{NMR}$ spectra of synthon 3a which confirm the presence of all the desired

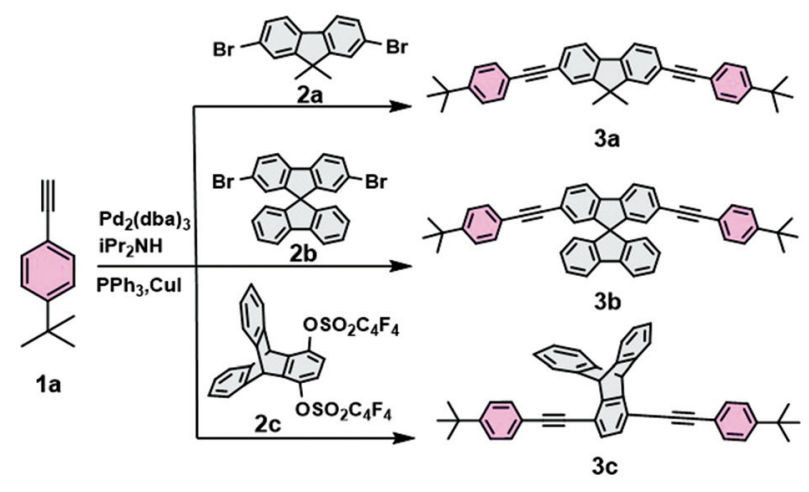

Scheme 1 Synthesis of comonomers 3a-c. 


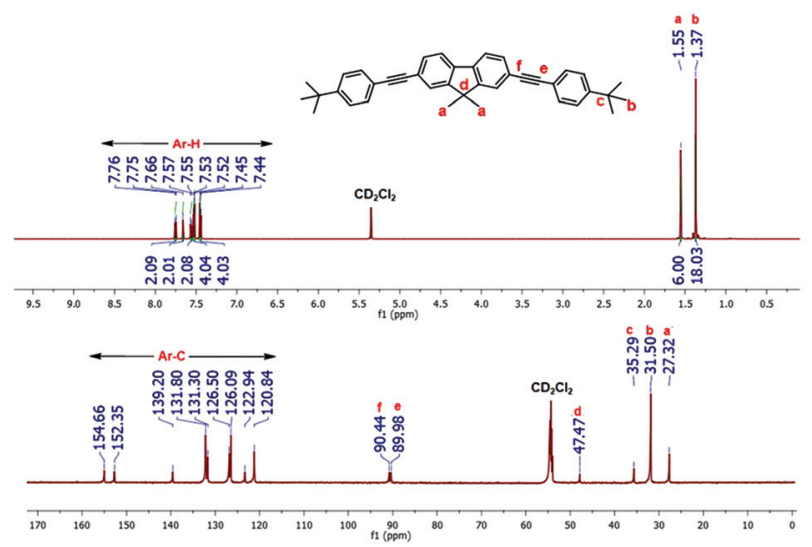

Fig. $1{ }^{1} \mathrm{H}$ (top) and ${ }^{13} \mathrm{C}$ (bottom) NMR of 3a recorded in $\mathrm{CD}_{2} \mathrm{Cl}_{2}$.

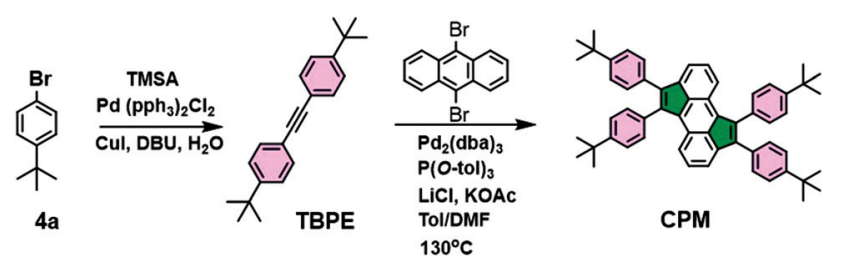

Scheme 2 Synthesis of prototypical monomer CPM.

peaks. All the aromatic protons and carbons of $\mathbf{3 a}$ were detected in the ranges of 7.4-7.7 ppm and 120.8-154.6 ppm, respectively. The ${ }^{1} \mathrm{H}$ NMR spectrum of 3 a shows the characteristic aliphatic peaks of the methyl groups of fluorene and t-butyl moieties at 1.5 and $1.3 \mathrm{ppm}$, respectively ( $c f$. peaks labeled $\mathbf{a}$ and $\mathbf{b}$ in Fig. 1). The ${ }^{13} \mathrm{C}$ NMR spectrum displays two peaks at 90.4 and $89.9 \mathrm{ppm}$, which are attributed to the characteristic sp carbons of $\mathbf{3 a}$ ( $c f$. peaks labeled $\mathbf{e}$ and $\mathbf{f}$ in Fig. 1). In addition, all the aliphatic peaks in the range of 47.4-27.3 ppm are in full agreement with the desired synthon 3a. Similarly, ${ }^{1} \mathrm{H}$ - and ${ }^{13} \mathrm{C}-\mathrm{NMR}$ spectra of comonomers $\mathbf{3 b}$ and $3 \mathbf{c}$ display the characteristic chemical shifts, and thus, confirm the formation of the desired products (see Fig. S1-3 and S9-11 in the ESI $\dagger$ ). Furthermore, electron-impact high-resolution mass spectrometry (EI-HRMS) of 3a-c reveal the formation of all the desired building blocks in high purity, as can be observed from the isotopic distribution (see Fig. S18-20 in the ESI $\dagger$ ).

In order to prove the feasibility of the cyclopentannulation reaction, a model test was carried out by reacting 9,10-dibromoanthracene DBA with two equivalents of 1,2-bis(4-(tertbutyl)phenyl)ethyne TBPE in a 1:1 DMF/toluene mixture at $130{ }^{\circ} \mathrm{C}$ (Scheme 2) affording the prototypical target $\mathbf{C P M}$ in $74 \%$ yield.

The structure of CPM was confirmed by ${ }^{1} \mathrm{H}$ - and ${ }^{13} \mathrm{C}-\mathrm{NMR}$ spectroscopy, high-resolution mass spectroscopy (HRMS), and hydrogen carbon-13 correlation 2D-NMR spectroscopy. Fig. 2 shows the ${ }^{1} \mathrm{H}$ NMR spectra of CPM where all the characteristic aromatic protons are revealed at $7.67 \mathrm{ppm}$ (doublet, labeled a), $7.50 \mathrm{ppm}$ (doublet, labeled b), and 7.34 ppm (triplet, labeled
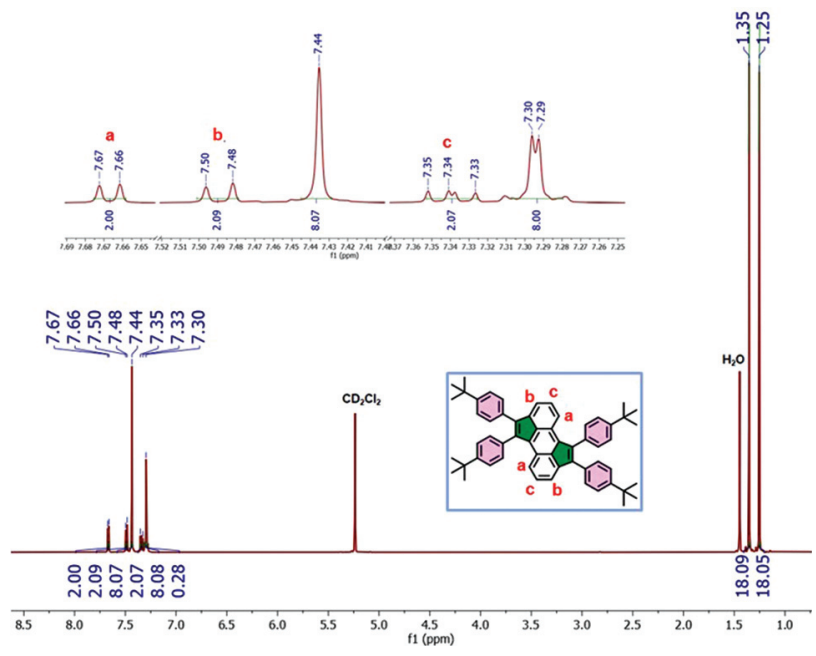

Fig. $2{ }^{1} \mathrm{H}$ NMR of CPM recorded in $\mathrm{CD}_{2} \mathrm{Cl}_{2}$.

c). The aliphatic t-butyl protons are detected at $1.35 \mathrm{ppm}$ and 1.25 ppm. ${ }^{13} \mathrm{C}-\mathrm{NMR}$ spectral analysis corroborates the above findings, and thus, further confirms the formation of the desired monomer CPM by revealing the presence of all the peaks at the expected chemical shifts. Formation of CPM is also supported by the $2 \mathrm{D}$ hydrogen carbon-13 correlation spectra which also confirm the sole formation of the desired product with the absence of any trace amount of side products (see Fig. S5, S13, and S17 in the ESI $\dagger$ ).

The analysis of CPM by electron-impact high-resolution mass spectrometry (EI-HRMS) confirms its formation in high purity, as revealed by the experimentally determined isotopic patterns when compared to the calculated ones (Fig. 3).

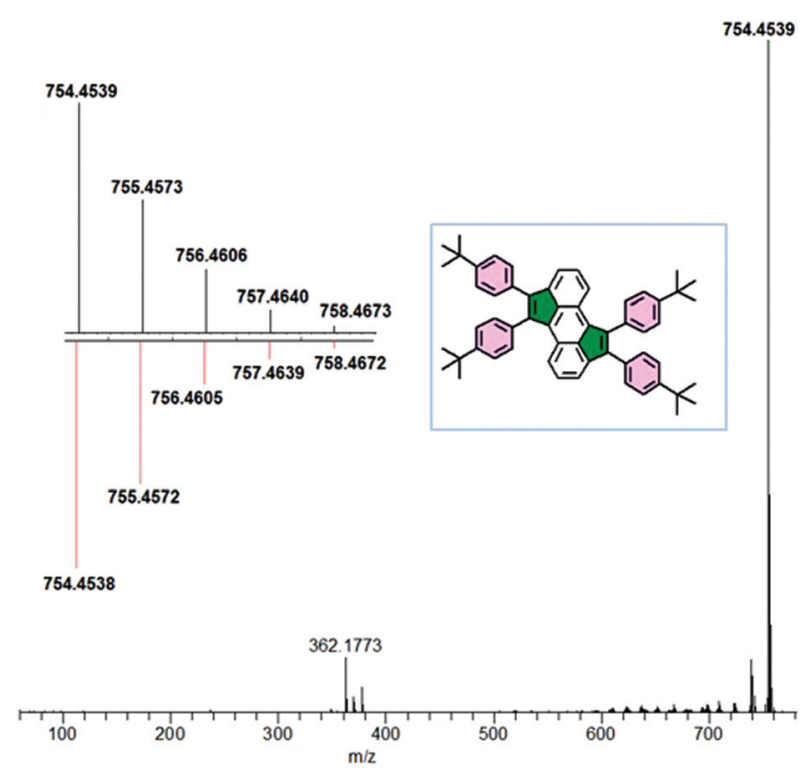

Fig. 3 El-HRMS spectrum of CPM; inset: calculated (down) and measured (up) isotopic patterns of $\mathrm{C}_{58} \mathrm{H}_{58}{ }^{*+}$. 


\section{Synthesis of copolymers CPP1-3}

As could be observed from Scheme 3, the conjugated polymers CPP1-3 were synthesized from the cyclopentannulation reaction of DBA with monomers 3a-c following the same conditions which were applied to prepare the prototypical monomer CPM described in Scheme 2. The polymerization was carried out by the reaction of a $0.1 \mathrm{M}$ solution of $3 \mathbf{a}-\mathbf{c}$ with an equimolar amount of DBA in the presence of a $\operatorname{pd}_{2}(\mathrm{dba})_{3}$ catalyst, a $\mathrm{p}(o \text {-tol })_{3}$ ligand, a KOAc base and LiCl in a $1: 1$ $\mathrm{DMF} /$ toluene solvent mixture at $130{ }^{\circ} \mathrm{C}$ over four days. CPP1-3 target polymers were isolated in excellent yields (86-97\%) and were found to be highly soluble in common organic solvents such as $\mathrm{CHCl}_{3}$, DCM, and THF. The high purity of CPP1-3 was confirmed by GPC analysis, and ${ }^{1} \mathrm{H}-$ and ${ }^{13} \mathrm{C}-\mathrm{NMR}$, FTIR, UVvis absorption and emission spectroscopy (see Fig. 4 and Fig. S6-8, S14-16, and S22-23 in the ESI $\dagger$ ).

The GPC results of CPP1-3 reveal that the average weight molar mass $\left(M_{\mathrm{w}}\right)$ ranges from 32.2 to $15.8 \mathrm{kDa}$, while the average number molecular mass $\left(M_{\mathrm{n}}\right)$ varies between 11.6 and $6.6 \mathrm{kDa}$, thus yielding polydispersity values $(\boxplus)$ varying from 2.4 to 2.8 (Fig. 4 and Table 1, entry $1-3$ ).

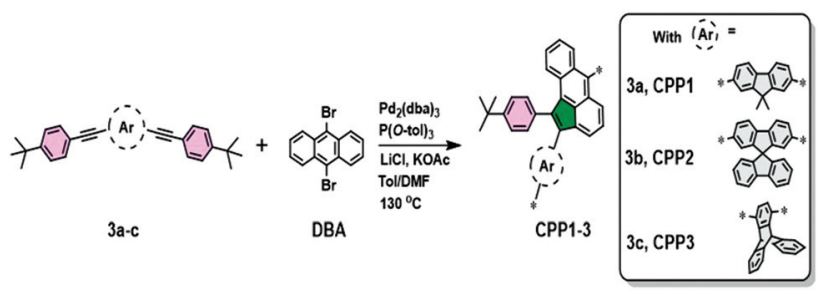

Scheme 3 Synthesis of conjugated polymers CPP1-3.

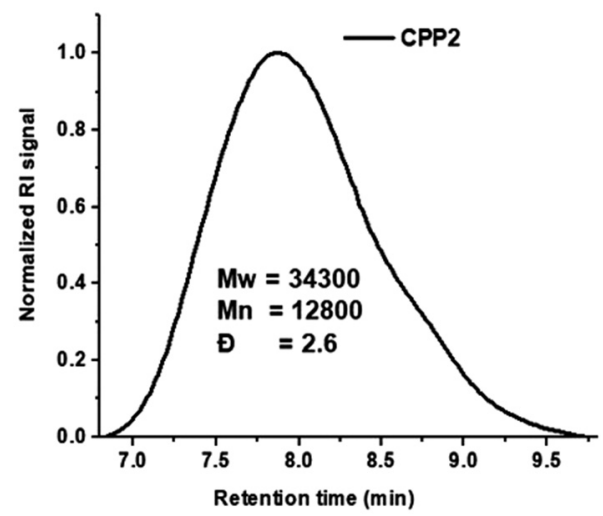

Fig. 4 Normalized GPC chromatogram of CPP2.

Table 1 GPC results of polymers CPP1-3

\begin{tabular}{lllll}
\hline Entry & Product & $M_{\mathrm{w}}\left(\mathrm{g} \mathrm{mol}^{-1}\right)$ & $M_{\mathrm{n}}\left(\mathrm{g} \mathrm{mol}^{-1}\right)$ & $D$ \\
\hline 1 & CPP1 & 15800 & 6600 & 2.4 \\
2 & CPP2 & 34300 & 12800 & 2.7 \\
3 & CPP3 & 32200 & 11600 & 2.8
\end{tabular}

Fig. 5 illustrates the comparative FT-IR absorption spectra of comonomer $\mathbf{3 c}$ and its corresponding polymer CPP3. The characteristic stretching and bending vibrations of the aliphatic C-H groups in 3c are observed at 2967 and $1440 \mathrm{~cm}^{-1}$, respectively. In addition, $3 \mathrm{c}$ divulges the characteristic $\mathrm{C} \equiv \mathrm{C}$ stretching vibrations at $2209 \mathrm{~cm}^{-1}$, which completely disappears in the FT-IR absorption spectrum of the corresponding polymer CPP3. The stretching and bending vibrations of the aliphatic $\mathrm{C}-\mathrm{H}$ groups in CPP3 are detected at 2960 and $1432 \mathrm{~cm}^{-1}$, respectively. It is noteworthy that the FT-IR spectrum of CPP3 discloses more pronounced aromatic stretching vibrations for $\mathrm{C}-\mathrm{C} \quad\left(1400-1600 \quad \mathrm{~cm}^{-1}\right)$ and $\mathrm{C}-\mathrm{H}$ (2960-3050 $\mathrm{cm}^{-1}$ ), when compared to those recorded for monomer 3c. This clearly indicates the full conversion of the ethynylene moieties into the corresponding conjugated polymers.

The photophysical properties of the target polymers were measured by means of UV-Vis absorption and fluorescence spectroscopy. CPP1 and CPP2 display similar features with a strong UV absorption band at $340 \mathrm{~nm}$, whereas CPP3, i.e. the polymer that contains triptycene units, discloses a strong absorption band at $395 \mathrm{~nm}$, thus revealing a red-shift by $55 \mathrm{~nm}$. Interestingly, the emission spectra of polymers CPP1-3 show two peak maxima, the first ranging from $\sim 403$ to $433 \mathrm{~nm}$, while the second being observed between 540 and $564 \mathrm{~nm}$ (Fig. 6).

\section{Iodine uptake studies}

Target polymers CPP1-3 offer several advantages, namely, their contorted structures, excellent solubility, and longrange conjugation. Whilst the former property could be explained by cyclopentannulation reaction, the last two properties could be attributed to the introduction of the specially designed polycondensed aromatic hydrocarbon comonomers $\mathbf{3 a - c}$, whose spiro centers prevent the target polymers CPP1-3 from aggregation and improve the overall polymer porosity. Therefore, the specially designed graphitelike structures of CPP1-3 prompted us to explore their iodine adsorption and desorption properties. Vapor iodine adsorption experiments were carried out gravimetrically according to a protocol reported in the literature. ${ }^{57,58}$ CPP1-3 target compounds were exposed to excess iodine vapors by taking a $20 \mathrm{mg}$ sample of each polymer in an open glass vial, which was in turn placed inside a sealed glass vessel that contained solid iodine at $80{ }^{\circ} \mathrm{C}$ under atmospheric pressure. The iodine uptake capacity of CPP1-3 was monitored gravimetrically as shown in Table 2. It was observed that after one hour of iodine exposure, $\sim 65 \%$ by weight was adsorbed by CPP2 while half of this amount i.e. $\sim 30 \mathrm{wt} \%$ was recorded for CPP1 and CPP3 (Table 2, entry 3). Subsequently, the iodine uptake by CPP2 reached $\sim 190$ wt\% after 24 hours, whereas an average of 135 wt\% was recorded for CPP1 and CPP3 for the same exposure period (Table 2, entry 9). The adsorption values showed little increase when the polymers were kept for 72 hours, thus, suggesting the saturation of CPP1-3, reaching maximum iodine uptake capacities of 153,200 , and 


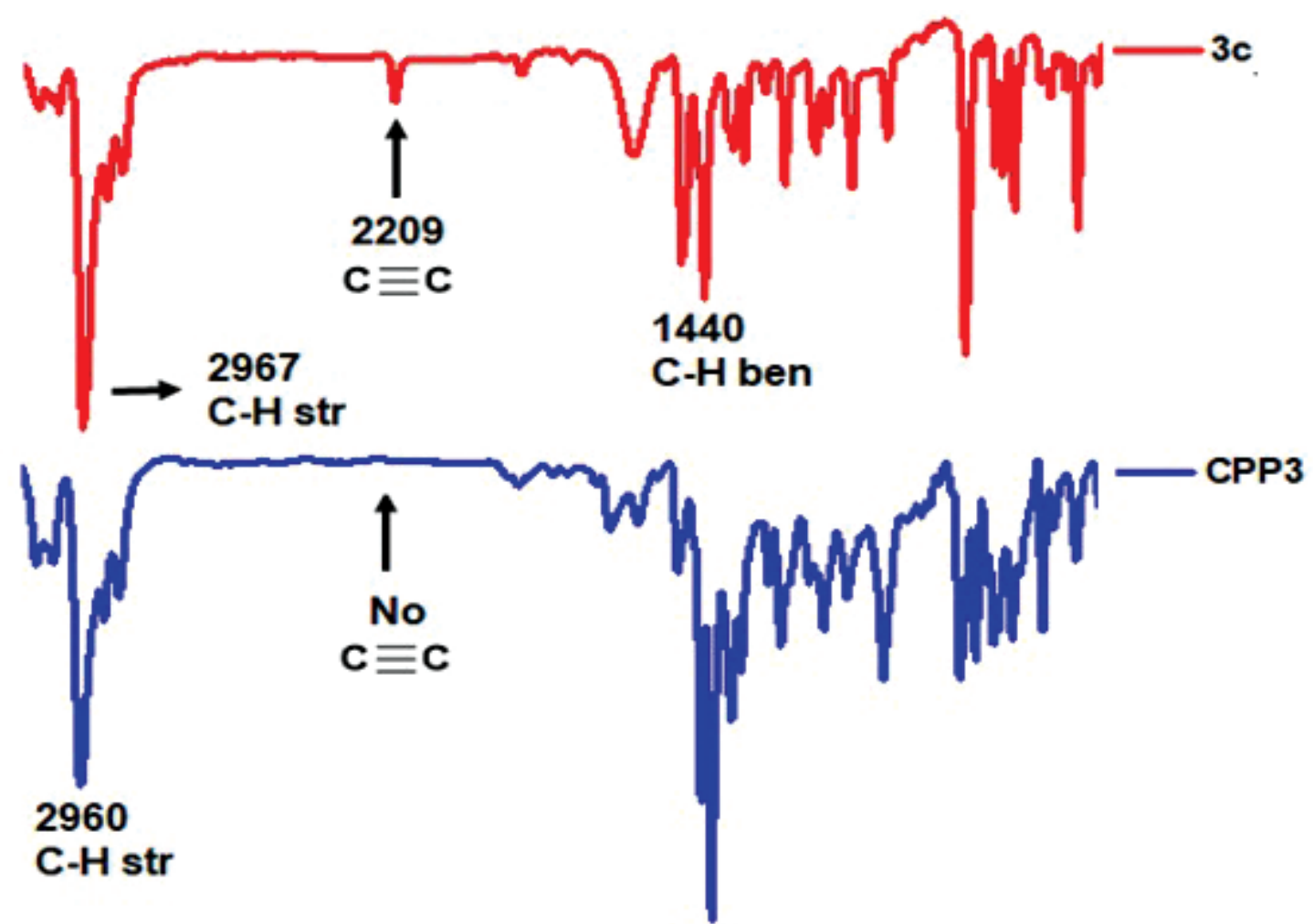

1432

C-H ben

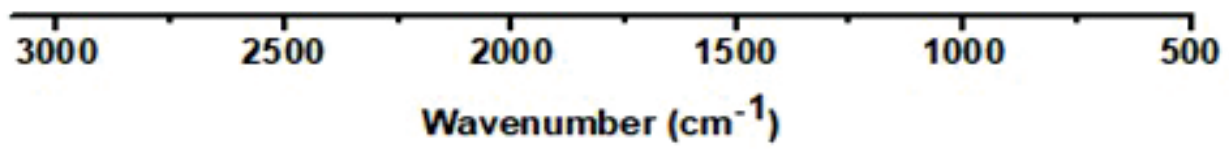

Fig. 5 Comparative FT-IR spectra of $3 c$ and CPP3.
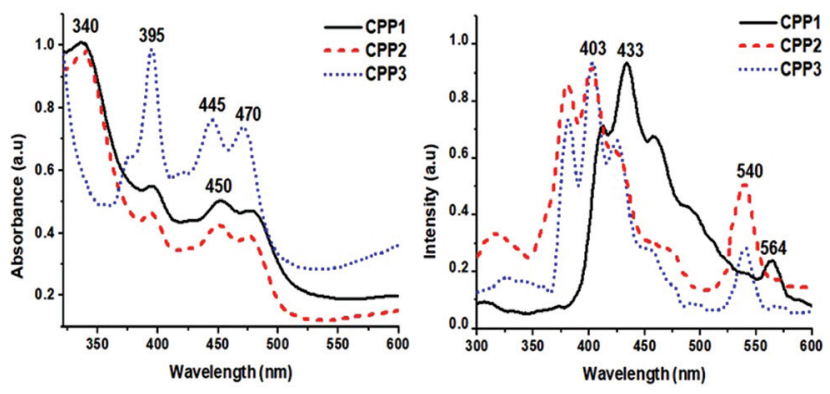

Fig. 6 Normalized UV-VIS absorption (left) and emission (right) spectra of CPP1-3 $\left(C_{M}=10^{-6} M\right.$ in THF).

$140 \mathrm{wt} \%$, respectively (Table 2 , entry 10). It is noteworthy that the iodine uptake capacity of the prototypical monomer CPM is just 32 wt\% after 72 hours of exposure to iodine vapors, which is far lower than that of its corresponding polymers CPP1-3.

The 200 wt $\%$ iodine uptake value of CPP2 is superior to those of polymers reported in the literature, and notable
Table 2 Summary of iodine adsorption of polymers CPP1-3

\begin{tabular}{lllllll}
\hline Entry & Time $^{a}$ & CPM $^{b}$ & CPP1 & CPP2 & CPP3 & Reused CPP2 \\
\hline 1 & 0 & - & - & - & - & - \\
2 & 0.5 & - & 13 & 45 & 9 & 43 \\
3 & 1 & - & 34 & 65 & 30 & 67 \\
4 & 2 & - & 47 & 80 & 45 & 82 \\
5 & 3 & - & 67 & 120 & 60 & 115 \\
6 & 4 & - & 93 & 140 & 85 & 138 \\
7 & 5 & - & 100 & 150 & 100 & 147 \\
8 & 6 & - & 107 & 160 & 115 & 153 \\
9 & 24 & 16 & 129 & 190 & 140 & 173 \\
10 & 72 & 32 & 153 & 200 & 140 & 180
\end{tabular}

${ }^{a}$ Hours. ${ }^{b}$ wt $\%$ iodine uptake.

among these are nitrogen-rich triptycene-based materials (NTP, 180 wt\%), ${ }^{59}$ calix[4]arene-based 2D macromolecules (CX4-NS, $114 \mathrm{wt} \%),{ }^{60}$ porphyrin and pyrene-based conjugated microporous polymers (Por-Py-CMP, $130 \mathrm{wt} \%),{ }^{61}$ nitrogen-containing materials (NRPPs, $192 \mathrm{wt} \%),{ }^{57}$ JLUE covalent organic polymer (JLUE-COP-3, up to $90.29 \%$ ), ${ }^{62}$ conjugated microporous polymers with thiophene units (SCMPs, $222 \mathrm{wt} \%),{ }^{34}$ 


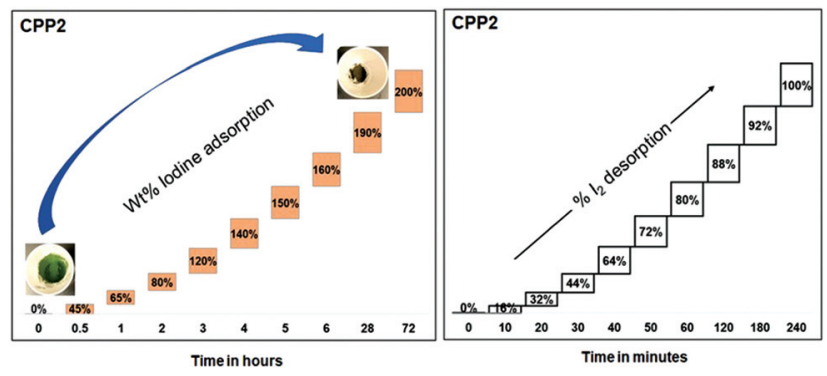

Fig. 7 CPP2 gravimetric adsorption (left) and desorption (right, heated at $125^{\circ} \mathrm{C}$ in air) of iodine as a function of time. Inset: crucible photographs showing the color change after iodine adsorption.

hierarchically porous adamantane-based macromolecules (202 wt\%), ${ }^{63}$ triazine-based covalent frameworks (TTPT, $177 \mathrm{wt} \%$ ), ${ }^{64}$ fluorine-enriched polymers (FCMP-600@1-4, up to $141 \mathrm{wt} \%)^{65}$ and many others. ${ }^{66,67}$

The iodine adsorbed by CPP1-3 could be released by simple heating of these latter polymers in air at $125{ }^{\circ} \mathrm{C}$. The complete $100 \%$ iodine desorption efficiency for the iodineloaded polymers ( $\mathbf{I}_{2} @ \mathbf{C P P 1} \mathbf{3}$ ) was recorded at different time intervals (Fig. 7 and Fig. S24 and S26 in the ESI $\dagger$ ). The reusable adsorption efficiency of the polymers was investigated using CPP2, which showed the maximum uptake capacity for iodine. For this, we first heated a sample of CPP2 fully loaded with iodine vapors ( $\mathbf{I}_{2} @ \mathbf{C P P} 2$ ) at $125{ }^{\circ} \mathrm{C}$ for 24 hours, in order to ensure the complete release of the adsorbate from the polymer backbone. The reactivated CPP2 was then exposed to iodine vapors and its uptake was recorded gravimetrically using the procedure described above, revealing an uptake pattern similar to that of a freshly prepared polymer (Table 2 ). It is worth mentioning that CPP1-3 undergo a color change from green/brown to black upon exposure to iodine vapors and return to their original color when heated to $125{ }^{\circ} \mathrm{C}$ in order to release the adsorbate (Fig. 7, inset).

Iodine desorption results were further supported by immersing CPP1-3 in ethanol, an excellent solvent for dissolving iodine but not the target polymers (Fig. 8 and Fig. S25 and $\mathrm{S} 27$ in the ESI $\dagger$ ). The iodine extraction in ethanol was studied by recording the UV-visible absorbance spectra at different time intervals (Fig. 8). A noticeable increase with time in the intensity of the absorbance maxima that correspond to iodine, i.e. $\sim 227 \mathrm{~nm}$ (due to $\mathrm{I}_{2}$ ), $\sim 290 \mathrm{~nm}$ and $\sim 359 \mathrm{~nm}$ (due to polyiodide ions), was observed which confirms the adsorbate release from CPP2 under ambient conditions. The amount of iodine released increased rapidly within the first 20 minutes and reached equilibrium after 45 minutes. The color of the solution changed from colorless to yellow (Fig. 8) which further confirms the iodine release in ethanol. These experimental observations strongly suggest that CPP1-3 can be employed as sorbent materials for efficient iodine vapor uptake. Moreover, once the polymers

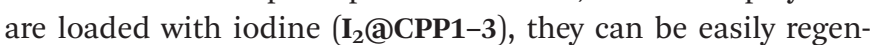
erated either by heating or soaking in ethanol, which makes the recycling process quite practical.

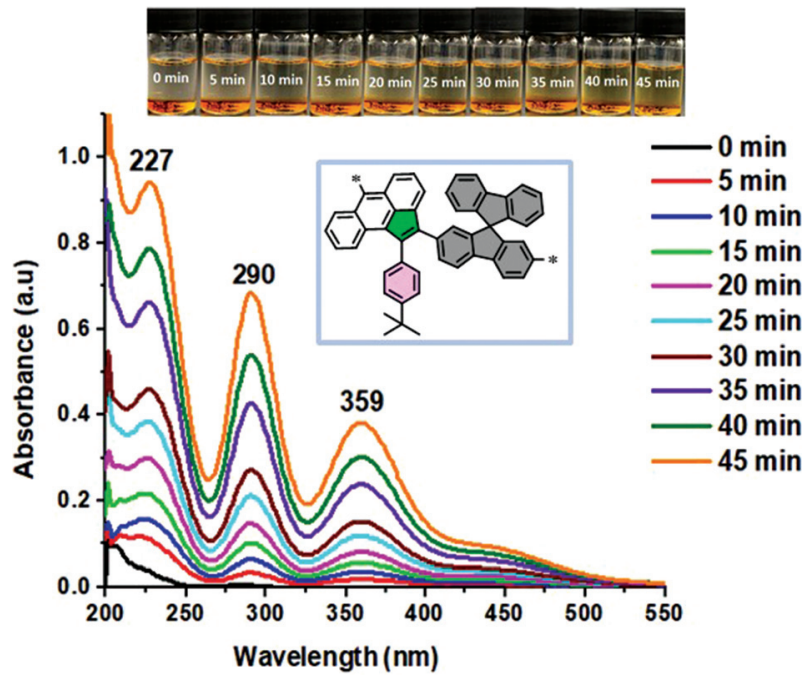

Fig. 8 UV-Vis absorption spectra upon immersion of $\mathrm{I}_{2}$ aCPP2 in ethanol. Inset: photographs of the solutions showing a color change upon immersion in ethanol.

\section{Conclusion}

We report the synthesis of three new conjugated polymers CPP1-3 via typical palladium-catalyzed cyclopentannulation reaction conditions. The target polymers, which contain contorted monomers, namely, dimethyl fluorene (CPP1), spirobifluorene (CPP2), and triptycene (CPP3), were isolated in excellent yields and found to have high relative weight-average molecular weights $\left(M_{\mathrm{w}}\right)$ in the range of $15.8-34.3 \mathrm{kDa}$ and a polydispersity index $\left(\nexists=M_{\mathrm{w}} / M_{\mathrm{n}}\right)$ varying between 2.4 and 2.8. Iodine vapor sorption studies of CPP1-3 reveal a high \% by weight uptake that reaches $200 \mathrm{wt} \%$ for CPP2 with the possibility to regenerate the polymer either by heating in ambient air or soaking in ethanol. This paves the way towards using these promising materials as versatile recyclable iodine gas adsorbents for applications in the field of environmental remediation.

\section{Conflicts of interest}

There are no conflicts to declare.

\section{Acknowledgements}

The project was partially supported by Kuwait Foundation for the Advancement of Sciences (KFAS) under project code PN1814SC-03. We would like to thank the general facilities projects GS01/01, GS01/03, GS01/05, GS03/01, and GS03/08 at Kuwait University.

\section{References}

1 A. Leventis, J. Royakkers, A. G. Rapidis, N. Goodeal, M. K. Corpinot, J. M. Frost, D.-K. Bučar, M. O. Blunt, 
F. Cacialli and H. Bronstein, J. Am. Chem. Soc., 2018, 140, 1622-1626.

2 A. Ichige, H. Saito, J. Kuwabara, T. Yasuda, J.-C. Choi and T. Kanbara, Macromolecules, 2018, 51, 6782-6788.

3 M. J. Sung, S. Yoon, S.-K. Kwon, Y.-H. Kim and D. S. Chung, ACS Appl. Mater. Interfaces, 2016, 8, 3117231178.

4 J. Yang, P. Cong, L. Chen, X. Wang, J. Li, A. Tang, B. Zhang, Y. Geng and E. Zhou, ACS Macro Lett., 2019, 8, 743-748.

5 K. Aoshima, M. Nomura and A. Saeki, ACS Omega, 2019, 4, 15645-15652.

6 H. Huang, H. Bin, Z. Peng, B. Qiu, C. Sun, A. LiebmanPelaez, Z.-G. Zhang, C. Zhu, H. Ade, Z. Zhang and Y. Li, Macromolecules, 2018, 51, 6028-6036.

7 J. Yuan, J. Ouyang, V. Cimrová, M. Leclerc, A. Najari and Y. Zou, J. Mater. Chem. C, 2017, 5, 1858-1879.

8 S.-H. Kang, A. Jeong, H. R. Lee, J. H. Oh and C. Yang, Chem. Mater., 2019, 31, 3831-3839.

9 Y. Du, H. Yao, L. Galuska, F. Ge, X. Wang, H. Lu, G. Zhang, X. Gu and L. Qiu, Macromolecules, 2019, 52, 4765-4775.

10 L. Zhang, Z. Wang, C. Duan, Z. Wang, Y. Deng, J. Xu, F. Huang and Y. Cao, Chem. Mater., 2018, 30, 8343-8351.

11 S. Shin, F. Menk, Y. Kim, J. Lim, K. Char, R. Zentel and T.-L. Choi, J. Am. Chem. Soc., 2018, 140, 6088-6094.

12 I. Choi, S. Yang and T.-L. Choi, J. Am. Chem. Soc., 2018, 140, 17218-17225.

13 F. Chen, Y. Jiang, Y. Sui, J. Zhang, H. Tian, Y. Han, Y. Deng, W. Hu and Y. Geng, Macromolecules, 2018, 51, 8652-8661.

14 T. M. Swager, Macromolecules, 2017, 50, 4867-4886.

15 T. Bura, S. Beaupre, M.-A. Legare, J. Quinn, E. Rochette, J. T. Blaskovits, F.-G. Fontaine, A. Pron, Y. Li and M. Leclerc, Chem. Sci., 2017, 8, 3913-3925.

16 A. Marrocchi, A. Facchetti, D. Lanari, S. Santoro and L. Vaccaro, Chem. Sci., 2016, 7, 6298-6308.

17 A. Hirose, K. Tanaka, R. Yoshii and Y. Chujo, Polym. Chem., 2015, 6, 5590-5595.

18 B. Alameddine, N. Baig, S. Shetty and S. Al-Mousawi, Polymer, 2019, 178, 121589.

19 N. Baig, S. Shetty, S. Al-Mousawi, F. Al-Sagheer and B. Alameddine, Mater. Today Chem., 2018, 10, 213-220.

20 K. Aravindu, E. Cloutet, C. Brochon, G. Hadziioannou, J. Vignolle, F. Robert, D. Taton and Y. Landais, Macromolecules, 2018, 51, 5852-5862.

21 Z. Wang, C. Wang, Y. Fang, H. Yuan, Y. Quan and Y. Cheng, Polym. Chem., 2018, 9, 3205-3214.

22 B. Alameddine, R. Sobhana Anju, S. Shetty, N. Baig, S. AlMousawi and F. Al-Sagheer, J. Polym. Sci., Part A: Polym. Chem., 2017, 55, 3565-3572.

23 C.-F. Yao, K.-L. Wang, H.-K. Huang, Y.-J. Lin, Y.-Y. Lee, C.-W. Yu, C.-J. Tsai and M. Horie, Macromolecules, 2017, 50, 6924-6934.

24 X. Yan, M. Xiong, J.-T. Li, S. Zhang, Z. Ahmad, Y. Lu, Z.-Y. Wang, Z.-F. Yao, J.-Y. Wang, X. Gu and T. Lei, J. Am. Chem. Soc., 2019, 141, 20215-20221.

25 J.-S. M. Lee and A. I. Cooper, Chem. Rev., 2020, 120, 2171-2214.
26 A. Rafiee and K. R. Khalilpour, in Polygeneration with Polystorage for Chemical and Energy Hubs, ed. K. R. Khalilpour, Academic Press, 2019, pp. 331-372, DOI: 10.1016/B978-0-12-813306-4.00011-2.

27 S. Chu and A. Majumdar, Nature, 2012, 488, 294-303.

28 B. K. Sovacool, Util. Policy, 2009, 17, 288-296.

29 D. Banerjee, A. J. Cairns, J. Liu, R. K. Motkuri, S. K. Nune, C. A. Fernandez, R. Krishna, D. M. Strachan and P. K. Thallapally, Acc. Chem. Res., 2015, 48, 211-219.

30 H. Ma, J.-J. Chen, L. Tan, J.-H. Bu, Y. Zhu, B. Tan and C. Zhang, ACS Macro Lett., 2016, 5, 1039-1043.

31 D. F. Sava, K. W. Chapman, M. A. Rodriguez, J. A. Greathouse, P. S. Crozier, H. Zhao, P. J. Chupas and T. M. Nenoff, Chem. Mater., 2013, 25, 2591-2596.

32 K. W. Chapman, P. J. Chupas and T. M. Nenoff, J. Am. Chem. Soc., 2010, 132, 8897-8899.

33 Y. Lin, X. Jiang, S. T. Kim, S. B. Alahakoon, X. Hou, Z. Zhang, C. M. Thompson, R. A. Smaldone and C. Ke, J. Am. Chem. Soc., 2017, 139, 7172-7175.

34 X. Qian, Z.-Q. Zhu, H.-X. Sun, F. Ren, P. Mu, W. Liang, L. Chen and A. Li, ACS Appl. Mater. Interfaces, 2016, 8, 21063-21069.

35 K. Kosaka, M. Asami, N. Kobashigawa, K. Ohkubo, H. Terada, N. Kishida and M. Akiba, Water Res., 2012, 46, 4397-4404.

36 F. Baig, K. Rangan, S. M. Eappen, S. K. Mandal and M. Sarkar, CrystEngComm, 2020, 22, 751-766.

37 M. Janeta, W. Bury and S. Szafert, ACS Appl. Mater. Interfaces, 2018, 10, 19964-19973.

38 X. Zhang, P. Gu, X. Li and G. Zhang, Chem. Eng. J., 2017, 322, 129-139.

39 A. Azadbakht, A. R. Abbasi and N. Noori, J. Inorg. Organomet. Polym. Mater., 2016, 26, 479-487.

40 T. Hasell, M. Schmidtmann and A. I. Cooper, J. Am. Chem. Soc., 2011, 133, 14920-14923.

41 C. Lee, S. Lee, G.-U. Kim, W. Lee and B. J. Kim, Chem. Rev., 2019, 119, 8028-8086.

42 Y. Xie, Y. Gong, M. Han, F. Zhang, Q. Peng, G. Xie and Z. Li, Macromolecules, 2019, 52, 896-903.

43 K. Geng, T. He, R. Liu, K. T. Tan, Z. Li, S. Tao, Y. Gong, Q. Jiang and D. Jiang, Chem. Rev., 2020, DOI: 10.1021/acs. chemrev.9b00550.

44 Y. Yano, N. Mitoma, H. Ito and K. Itami, J. Org. Chem., 2020, 85, 4-33.

45 W. Wang, H. Chen, H. Y. Zhu, Y. L. Huang and J. W. Yang, Chem. - Asian J., 2017, 12, 3016-3026.

46 I. C.-Y. Hou, Y. Hu, A. Narita and K. Müllen, Polym. J., 2017, $\mathbf{5 0 ,} 3$.

47 B. Alameddine, N. Baig, S. Shetty, S. Al-Mousawi and F. AlSagheer, Polymer, 2018, 154, 233-240.

48 Z. Zeng, X. Shi, C. Chi, J. T. Lo, J. Casado and J. Wu, Chem. Soc. Rev., 2015, 44, 6578-6596.

49 Z.-X. Low, P. M. Budd, N. B. McKeown and D. A. Patterson, Chem. Rev., 2018, 118, 5871-5911.

50 B. Comesaña-Gándara, J. Chen, C. G. Bezzu, M. Carta, I. Rose, M.-C. Ferrari, E. Esposito, A. Fuoco, J. C. Jansen 
and N. B. McKeown, Energy Environ. Sci., 2019, 12, 27332740.

51 D. Reinhard, W.-S. Zhang, F. Rominger, R. Curticean, I. Wacker, R. Schröder Rasmus and M. Mastalerz, Chem. Eur. J., 2018, 24, 11433-11437.

52 I. Rose, C. G. Bezzu, M. Carta, B. Comesana-Gandara, E. Lasseuguette, M. C. Ferrari, P. Bernardo, G. Clarizia, A. Fuoco, J. C. Jansen, K. E. Hart, T. P. Liyana-Arachchi, C. M. Colina and N. B. McKeown, Nat. Mater., 2017, 16, 932-937.

53 X. Zhu, S. R. Bheemireddy, S. V. Sambasivarao, P. W. Rose, R. T. Guzman, A. G. Waltner, K. H. DuBay and K. N. Plunkett, Macromolecules, 2016, 49, 127-133.

54 S. R. Bheemireddy, M. P. Hautzinger, T. Li, B. Lee and K. N. Plunkett, J. Am. Chem. Soc., 2017, 139, 5801-5807.

55 Z. Zhu and T. M. Swager, Org. Lett., 2001, 3, 3471-3474.

56 B. Alameddine, N. Baig, S. Shetty, S. Al-Mousawi and F. Al-Sagheer, J. Polym. Sci., Part A: Polym. Chem., 2018, 56, 931-937.

57 Y. H. Abdelmoaty, T.-D. Tessema, F. A. Choudhury, O. M. El-Kadri and H. M. El-Kaderi, ACS Appl. Mater. Interfaces, 2018, 10, 16049-16058.
58 Y. Gao, Y. Deng, H. Tian, J. Zhang, D. Yan, Y. Geng and F. Wang, Adv. Mater., 2017, 29, 1606217.

59 R. M. Weiss, A. L. Short and T. Y. Meyer, ACS Macro Lett., 2015, 4, 1039-1043.

60 D. Shetty, T. Skorjanc, J. Raya, S. K. Sharma, I. Jahovic, K. Polychronopoulou, Z. Asfari, D. S. Han, S. Dewage, J.-C. Olsen, R. Jagannathan, S. Kirmizialtin and A. Trabolsi, ACS Appl. Mater. Interfaces, 2018, 10, 17359-17365.

61 K. C. Park, J. Cho and C. Y. Lee, RSC Adv., 2016, 6, 7547875481.

62 H. Guan, D. Zou, H. Yu, M. Liu, Z. Liu, W. Sun, F. Xu and Y. Li, Front. Mater., 2019, 6(12), DOI: 10.3389/fmats. 2019.00012.

63 D. Chen, Y. Fu, W. Yu, G. Yu and C. Pan, Chem. Eng. J., 2018, 334, 900-906.

64 T. Geng, W. Zhang, Z. Zhu, G. Chen, L. Ma, S. Ye and Q. Niu, Polym. Chem., 2018, 9, 777-784.

65 G. Li, C. Yao, J. Wang and Y. Xu, Sci. Rep., 2017, 7, 13972.

66 M. Ansari, A. Alam, R. Bera, A. Hassan, S. Goswami and N. Das, J. Environ. Chem. Eng., 2019, DOI: 10.1016/j. jece.2019.103558, In Press.

67 M. Liu, C. Yao, C. Liu and Y. Xu, Sci. Rep., 2018, 8, 14071. 